\title{
Anomalias dentárias em indivíduos com fissura transforame incisivo unilateral e o tratamento endodôntico
}

\section{Dental anomalies in individuals with unilateral cleft lip and palate and endodontic treatment}

Andrea Cardoso Pereira* Celso Kenji Nishiyama**

Lidiane de Castro Pinto ${ }^{* * *}$

\section{Resumo}

Objetivos: determinar a prevalência de anomalias dentárias nos dentes no lado da fissura labiopalatina em indivíduos com fissura transforame incisivo unilateral e relacionar essas anomalias com as dificuldades no tratamento endodôntico, quando necessário. Sujeitos e método: a análise comparativa foi realizada nos dentes adjacentes à fissura e em seus homólogos correspondentes por meio de radiografias panorâmicas. A observação radiográfica foi analisada por um examinador com o auxílio de uma lupa com lente de vidro em negatoscópio vertical da Sala de Interpretação Radiográfica do HRAC-USP. A amostra constava de indivíduos com idades entre 9 e 37 anos, com presença de dentes anteriores permanentes com no mínimo um par de homólogos e em estado de conservação coronária e radicular que permitisse a interpretação radiográfica de todo o espaço pulpar e com ausência de tratamento endodôntico e ortodôntico. Resultados: foram analisadas 592 radiografias panorâmicas, das quais 106 estavam dentro dos critérios de inclusão. A anomalia mais encontrada foi a dilaceração $(78,30 \%)$, seguida da giroversão $(24,53 \%)$, microdontia $(15,9 \%)$ e macrodontia $(1,89 \%)$. Para análise estatística foi aplicado o teste exato de Fisher, e apenas a macrodontia não apresentou diferença estatística significativa. $O$ incisivo central esquerdo foi o dente mais acometido por anomalias $(58,82 \%)$. O gênero masculino foi o mais prevalente $(66,04 \%)$, e a maioria dos indivíduos apresentou fissura transforame incisivo do lado esquerdo $(68,87 \%)$.
Conclusão: as anomalias dentárias encontradas neste estudo podem alterar o tratamento endodôntico, e o profissional deve reconhecê-las e tomar os devidos cuidados e precauções durante o tratamento.

Palavras-chave: Endodontia. Fissura palatina. Radiografia panorâmica.

\section{Introdução}

As fissuras labiopalatinas constituem uma grande fração de todos os defeitos congênitos humanos e são notáveis por sua etiologia complexa e morbidade significativa ao longo da vida. $\mathrm{O}$ aumento da incidência desses defeitos pode ser atribuído à diminuição da mortalidade e da morbidade pós-natal e pós-operatória e ao aumento dos fatores epidemiológicos genéticos e ambientais ${ }^{1}$. Eles afetam aproximadamente um em cada 700 nascimentos, uma frequência que pode variar de acordo com a região geográfica e o nível socioeconômico. Coletivamente, a fissura labiopalatina apresenta um grande impacto clínico, exigindo atendimento cirúrgico, odontológico, fonoaudiológico e psicológico durante a infância e a adolescência ${ }^{2}$.

\footnotetext{
Especialista em Endodontia HRAC-USP.

Doutor em Endodontia FOAR/Unesp, Chefe do Setor de Endodontia do Hospital de Reabilitação de Anomalias Craniofaciais, Universidade de São Paulo (HRAC-USP), Bauru, SP, Brasil.

*** Mestra em Patologia Bucal FOB/USP, Professora do setor de Endodontia do Hospital de Reabilitação de Anomalias Craniofaciais, Universidade de São Paulo (HRAC-USP), Bauru, SP, Brasil.
} 
A interação etiológica complexa das fissuras labiopalatinas, intercalando predisposição genética, hereditariedade e os fatores teratogênicos extragenéticos, ditos ambientais, dificulta esclarecer aos pais o motivo de seu surgimento. No entanto, este pode ser atribuído a uma fatalidade biológica, por ser difícil identificar um fator causal específico na maioria das fissuras ${ }^{2}$. Alguns estudos têm sugerido que a ingestão materna de ácido fólico durante a gravidez precoce pode reduzir os riscos de ocorrência das fissuras labiopalatinas. No entanto, os seus efeitos globais são inconsistentes ${ }^{3}$. Investigando-se as variações genéticas que influenciam a absorção celular, o transporte e o metabolismo do ácido fólico, poderão ser obtidos maiores entendimentos sobre 0 papel dessa vitamina na patogênese das fissuras ${ }^{4}$.

Quando comparado com a população em geral, os indivíduos com fissuras labiopalatinas apresentam maior prevalência de anomalias dentárias, tais como variações no número de dentes e posição e dimensões reduzidas dos dentes, a maioria dos quais estão localizados na área da fissura ${ }^{5}$. Entre as anomalias, destacam-se o dens in dente, taurodontia, hipodontia, dilaceração, fusão, geminação, dentes girovertidos e supranumerários, sendo o exame radiográfico considerado complementar, nestes casos, fundamental na observação de defeitos e variações na estrutura, tamanho, forma e posição dos elementos dentários ${ }^{6-9}$.

O objetivo deste trabalho é realizar criteriosa análise radiográfica do espaço pulpar e suas possíveis alterações relacionadas com as anomalias dentárias que possam comprometer ou alterar o tratamento endodôntico nos indivíduos com fissura.

\section{Sujeitos e método}

Este trabalho foi aprovado pelo Comitê de Ética em Pesquisa em Seres Humanos do Hospital de Reabilitação de Anomalias Craniofaciais (HRAC-USP) sob ofício de $\mathrm{n}^{\circ} 69 / 2011$. A partir de estudo radiográfico dos indivíduos matriculados no HRAC-USP na cidade de Bauru-SP, foi realizada análise comparativa dos dentes adjacentes à fissura e seus homólogos correspondentes. Para a seleção da amostra foram exigidos os seguintes requisitos: indivíduos com fissura transforame incisivo unilateral direita ou esquerda; do gênero feminino ou masculino; com idade acima de 9 anos; existência de radiografias panorâmicas no arquivo do Setor de Radiologia do HRAC-USP, em boas condições de contraste e nitidez; presença de dentes anteriores superiores permanentes com no mínimo um par de homólogos e em estado de conservação coronária e radicular que permitisse a interpretação radiográfica de todo o espaço pulpar; ausência de tratamento endodôntico e ortodôntico; registros contendo identificação do indivíduo (número do prontuário do HRAC-USP, nome, idade, gênero), especificação dos homólogos adjacentes à fissura e não adjacentes e relação das prováveis anomalias (macrodontia, microdontia, giroversão, geminação, fusão, raízes supranumerárias, dilaceração, dens in dente). A observação radiográfica foi realizada por um examinador com o auxílio de uma lupa com lente de vidro, aumento $3 \mathrm{x}$ e $75 \mathrm{~mm}$ de diâmetro, em negatoscópio vertical da Sala de Interpretação Radiográfica do HRAC-USP.

\section{Resultados}

Foram analisadas 592 radiografias panorâmicas, das quais 106 estavam dentro dos critérios de inclusão. A idade dos indivíduos variou de 9 a 37 anos, e a média foi de 17,5 anos. Os resultados deste estudo estão expressos em forma de tabelas. A Tabela 1 mostra a comparação relacionando a presença de anomalias nos lados adjacentes e não adjacentes à fissura, na qual se observa uma diferença estatística significativa, com exceção da macrodontia.

Tabela 1 - Comparação relacionando a presença de anomalias nos lados adjacente e não adjacente à fissura

\begin{tabular}{l|c|c|c}
\hline \multicolumn{1}{c|}{ Anomalia } & $\begin{array}{c}\text { Lado adjacente } \\
\text { à fissura n (\%) }\end{array}$ & $\begin{array}{c}\text { Lado não adjacente } \\
\text { à fissura n (\%) }\end{array}$ & $\mathrm{p}$ \\
\hline Dilaceração & $83(78,30)$ & $18(16,98)$ & $<0,01^{*}$ \\
Giroversão & $26(24,53)$ & $1(0,94)$ & $<0,01^{*}$ \\
Microdontia & $16(15,09)$ & $3(2,83)$ & $<0,01^{*}$ \\
Macrodontia & $2(1,89)$ & $0(0,00)$ & $0,50 \mathrm{~ns}$ \\
\hline
\end{tabular}

- associação significativa

ns - associação não significativa

A Tabela 2 mostra a comparação relacionando a presença de anomalias nos dentes adjacentes e não adjacentes à fissura, na qual também se observa uma diferença estatística significativa. Em ambos os resultados expressos nas tabelas foi aplicado o teste exato de Fisher. 
Tabela 2 - Comparação relacionando a presença de anomalias nos dentes adjacentes e não adjacentes à fissura

\begin{tabular}{l|c|c|c}
\multicolumn{1}{c|}{ Dente } & Lado adjacente à fissura n (\%) & Lado não adjacente à fissura $\mathrm{n}(\%)$ & $\mathrm{p}$ \\
\hline Incisivo central direito & $18(62,07)$ & $6(8,70)$ & $<0,01^{*}$ \\
Incisivo lateral direito & $9(81,82)$ & $5(8,93)$ & $<0,01^{*}$ \\
Canino direito & $17(60,71)$ & $4(5,71)$ & $<0,01^{*}$ \\
Incisivo central esquerdo & $40(58,82)$ & $4(13,79)$ & $<0,01^{*}$ \\
Incisivo lateral esquerdo & $23(65,71)$ & $2(8,00)$ & $<0,01^{*}$ \\
Canino esquerdo & $27(40,91)$ & $1(3,57)$ & $<0,01^{*}$ \\
\hline
\end{tabular}

*- associação significativa

A Tabela 3 mostra o total de dentes analisados nos lados adjacentes e não adjacentes à fissura.

Tabela 3 - Total de dentes analisados adjacentes e não adjacentes à fissura

\begin{tabular}{l|c|c}
\hline \multicolumn{1}{c|}{ Dente } & Lado adjacente à fissura $\mathrm{n}(\%)$ & Lado não adjacente à fissura $\mathrm{n}(\%)$ \\
\hline Incisivo central direito & $29(12,24)$ & $69(24,91)$ \\
Incisivo lateral direito & $11(4,64)$ & $56(20,22)$ \\
Canino direito & $28(11,81)$ & $70(25,27)$ \\
Incisivo central esquerdo & $68(28,69)$ & $29(10,47)$ \\
Incisivo lateral esquerdo & $35(14,77)$ & $25(9,03)$ \\
Canino esquerdo & $66(27,85)$ & $28(10,11)$ \\
\hline
\end{tabular}

As Tabelas 4 e 5 mostram a prevalência dos indivíduos quanto ao gênero e ao lado da fissura, respectivamente, e ambas representam resultado descritivo.

Tabela 4 - Prevalência dos indivíduos quanto ao gênero

\begin{tabular}{l|c|c}
\hline \multicolumn{1}{c|}{ Gênero } & Frequência & Porcentagem (\%) \\
\hline Masculino & 70 & 66,04 \\
Feminino & 36 & 33,96 \\
Total & 106 & 100 \\
\hline
\end{tabular}

Tabela 5 - Prevalência dos indivíduos quanto ao lado da fissura

\begin{tabular}{l|c|c}
\hline \multicolumn{1}{c|}{ Lado da fissura } & Frequência & Porcentagem (\%) \\
\hline Esquerdo & 73 & 68,87 \\
Direito & 33 & 31,13 \\
Total & 106 & 100 \\
\hline
\end{tabular}

\section{Discussão}

A ocorrência de fissuras labiopalatinas e o desenvolvimento dos germes dentários têm estreita relação embriológica em termos de tempo e posição anatômica. Sugere-se que os genes da fissura podem produzir distúrbios nos tecidos, afetando a lâmina dentária ${ }^{10}$. Indivíduos com fissuras apresentam maior prevalência de anomalias dentárias que indivíduos sem fissura, e a gravidade da anomalia parece estar diretamente relacionada com a gravidade da fissura. Estudos recentes têm implicado que a presença de anomalias dentárias pode representar um marcador clínico adicional para as fissuras orais, propondo um fundo genético comum entre as condições ${ }^{11}$.

O estudo detalhado das anomalias é essencial para compreender como elas podem levar a má oclusão, deformidades estéticas, acidentes e complicações durante a extração dentária ou tratamento endodôntico. A fim de diagnosticar essas anomalias, além de observações clínicas, exames como a radiografia são essenciais e desempenham um importante papel no diagnóstico diferencial. Neste estudo, a radiografia panorâmica foi escolhida para avaliar a presença de anomalias dentárias, pois se trata de uma técnica radiológica que permite produzir uma única imagem da estrutura facial, incluindo a maxila e mandíbula e suas estruturas de apoio. Essa técnica possui muitas vantagens, tais como ampla cobertura de dentes, baixa dose de radiação e tempo curto de processamento. O reconhecimento precoce das anomalias dentárias é importante do ponto de vista terapêutico, já que elas podem ocasionar várias complicações ${ }^{12}$.

Neste trabalho, observa-se maior predominância das fissuras labiopalatinas no gênero masculino, o que corrobora os achados de outros autores, com exceção das fissuras pós-forame incisivo, que acometem mais o gênero feminino $0^{13-16}$. 
A fissura transforame incisivo unilateral foi escolhida por permitir a comparação dos dentes com o lado não fissurado. A maior prevalência desse tipo fissura do lado esquerdo, neste trabalho, é concordante com o resultado de Freitas et al. ${ }^{13}$, que encontraram ser esta a de maior frequência no HRAC-USP.

A dilaceração (Fig. 1) é o resultado da anomalia de desenvolvimento que provoca uma mudança abrupta na inclinação axial entre a coroa e a raiz de um dente. Durante a odontogênese, qualquer fator que possa mudar o metabolismo e as condições físicas ao redor do germe dentário pode perturbar o seu desenvolvimento. Possíveis fatores que contribuem são: lesões traumáticas aos dentes decíduos, patogê- neses de um predecessor primário, presença de um cisto adjacente, odontoma ou dente supranumerário, genética ou fatores de desenvolvimento. As dilacerações podem se apresentar de várias maneiras, incluindo um atraso na erupção do dente afetado, retenção prolongada de um dente decíduo ou dentes assintomáticos ${ }^{6}$. Neste estudo, a dilaceração foi a anomalia mais encontrada, num total de $78,30 \%$ no lado adjacente à fissura e de $16,98 \%$ no lado não adjacente. Esses achados são superiores aos de outros trabalhos, que encontraram $19,2 \%$ dessa anomalia em indivíduos com fissuras labiopalatinas ${ }^{9}$ e $15 \%^{12}$ e $9,5 \%{ }^{17}$ em indivíduos sem fissuras.

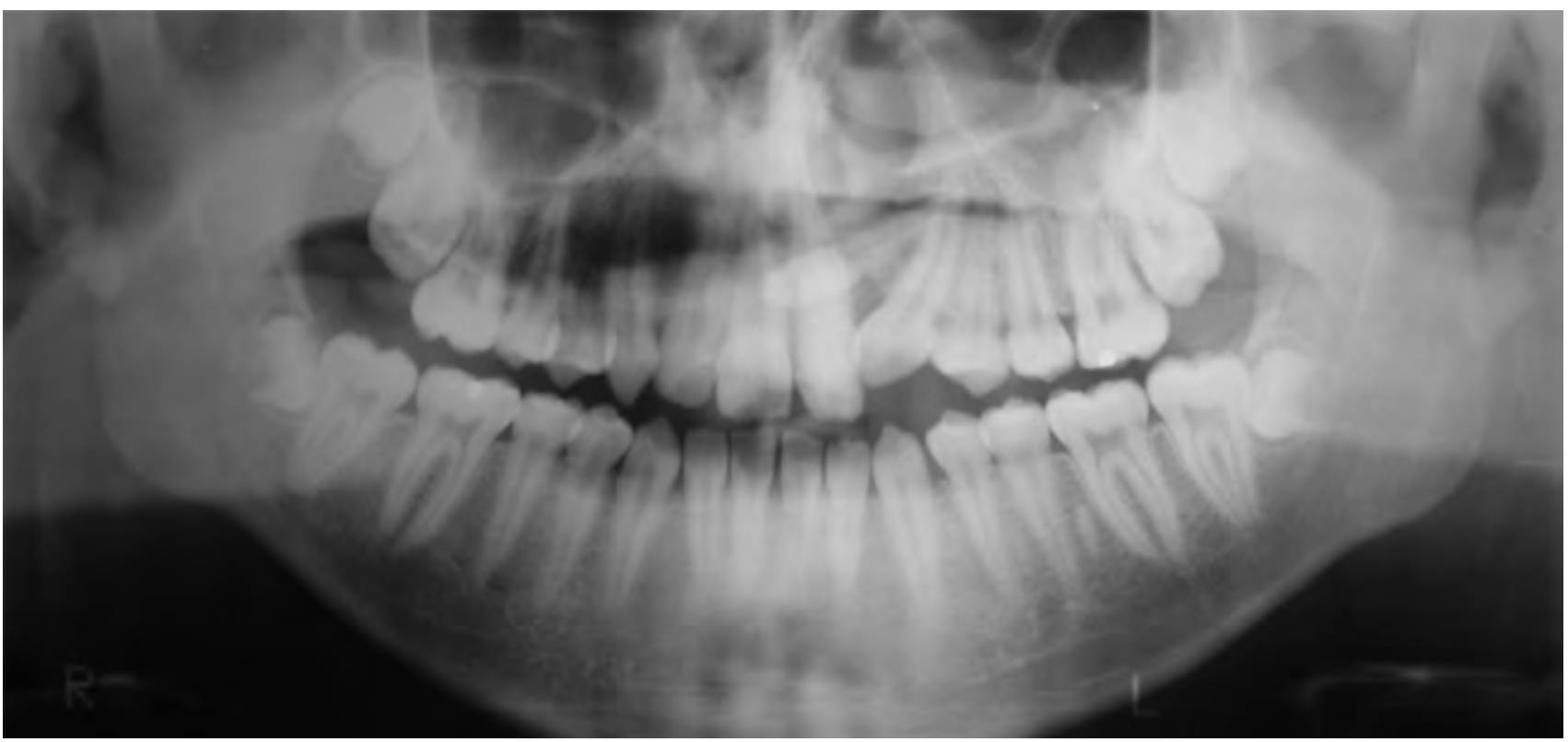

Figura 1 - Radiografia panorâmica mostrando dilaceração no canino superior esquerdo

O reconhecimento e o diagnóstico da dilaceração são essenciais para qualquer dente que requer tratamento endodôntico, extração ou movimento ortodôntico. Nos dentes dilacerados, o acesso à cavidade pulpar deve ser rigorosamente seguido por meio de boas radiografias pré-operatórias e de trabalho. $\mathrm{O}$ acesso deve ser o mais direto possível ao terço apical do canal (dentro dos limites da dilaceração), e deve ser feita a pré-curvatura de todos os instrumentos a serem usados, além de uma eficiente irrigação. A movimentação ortodôntica em dentes dilacerados pode causar uma severa reabsorção da raiz, o que pode complicar seriamente o tratamento endodôntico. Outra complicação no tratamento endodôntico desses casos é a incapacidade da lima em acompanhar a curvatura do canal, o que pode resultar em transporte apical, perfuração e quebra do instrumento. Portanto, é essencial pré-curvar todos os instrumentos para permitir que as limas possam seguir as curvaturas, respeitando a anatomia original do canal principal, e não apenas cortar em linha reta. Instrumentos feitos a partir de níquel-titânio podem ajudar a manter a curvatura dos canais radiculares em muitos dentes. No entanto, em geral, canais radiculares dilacerados não são adequados para o uso de instrumentos rotatórios devido à extensão das curvaturas que devem ser negociadas. Todos os instrumentos utilizados dentro dos canais radiculares devem ser descartados após o uso na prevenção de fraturas. Em relação à técnica de obturação, a condensação lateral pode ser muito eficaz na maioria dos dentes, mas em dentes dilacerados essa técnica pode ser difícil e, às vezes, impossível. No entanto, se esta for escolhida, é recomendável o uso de espaçadores de níquel-titânio para o preenchimento de canais radiculares acentuadamente curvos, visto que possibilitam a penetração em profundidade e distribuição das forças de maneira mais uniforme que os de aço inoxidável ${ }^{6}$. Outra opção de tratamento para os dentes dilacerados quando o tratamento convencional não for possível é realizar a cirurgia paraendodôntica, através da apicectomia $^{18,19}$

Dentes girovertidos (Fig. 2) podem ser classificados quando a superfície mesial ou a superfície distal dos dentes estiver desviada a partir da linha da arcada dentária. Essa informação pode ser obtida através de radiografias, registros dentários e mode- 
los de gesso ${ }^{20}$. No estudo de Tortora et al. ${ }^{21}$ (2008), a giroversão em indivíduos com fissura unilateral de lábio e palato esteve presente em $42,7 \%$ dos incisivos centrais e em $6,1 \%$ dos incisivos laterais, e no lado não fissurado esteve presente em $20,7 \%$ e $9,7 \%$ nos incisivos centrais e laterais, respectivamente. Lai et al. ${ }^{20}$ (2009) observaram a giroversão em 78,1\% dos indivíduos com fissura unilateral de lábio e palato e 19,2\% no lado não fissurado. Esses achados são superiores aos do nosso estudo, em que se encontrou a giroversão em $24,53 \%$ nos dentes no lado adjacente à fissura e $0,94 \%$ no lado não adjacente. Dentes girovertidos oferecem dificuldades ao trata- mento endodôntico, como o acesso e a visibilidade ao canal radicular, sendo muitas vezes necessário o acesso pela face vestibular ou faces proximais, o que normalmente se realiza pela palatina ou lingual. $\mathrm{O}$ isolamento absoluto também é dificultado, necessitando de alguns métodos auxiliares, como o uso de grampos especiais, amarrias, cianocrilato para fixar o dique de borracha e reconstruções com resina. As radiografias, igualmente, devem ser realizadas com mais cautela devido a essas alterações de posição, necessitando, em alguns casos, de mudanças na angulação do feixe de Rx, e o localizador foraminal eletrônico pode ser usado no momento da odontometria.

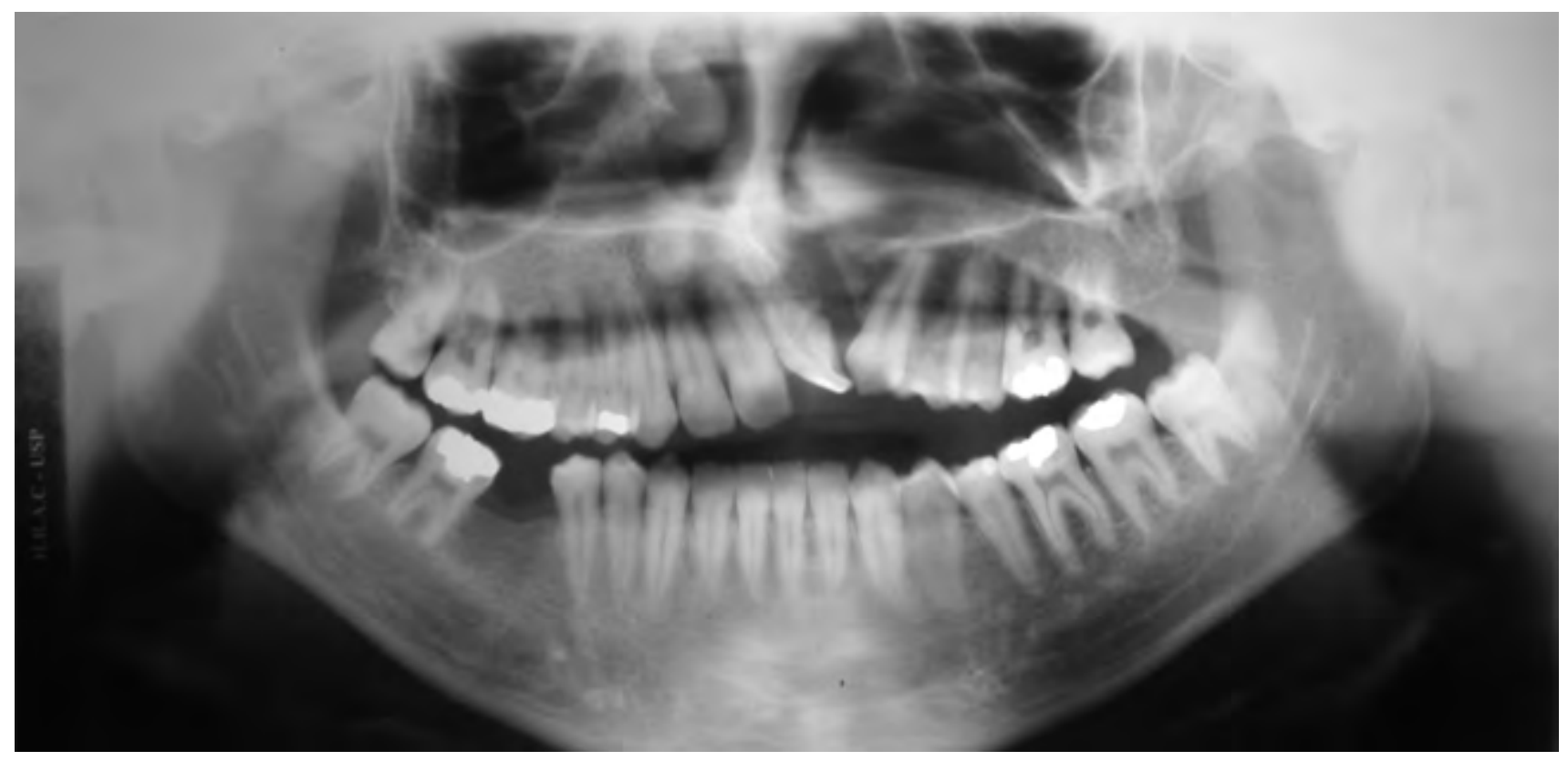

Figura 2 - Radiografia panorâmica mostrando giroversão no incisivo central superior esquerdo

A microdontia e a macrodontia podem ser consideradas se existirem um ou mais dentes menores ou maiores do que os classificados dentro da normalidade, ou seja, se eles estiverem fora dos limites normais de variação $0^{20}$. Neste trabalho, a microdontia (Fig. 3) foi encontrada em 15,09\% dos indivíduos no lado adjacente à fissura e em $2,83 \%$ no lado não adjacente. Já o estudo de Jamal et al. ${ }^{9}$ (2010) assinalou $37,2 \%$ de indivíduos com microdontia, e Akcam et al. ${ }^{5}$ (2010) encontraram uma prevalência de $6,1 \%$ dessa anomalia em indivíduos com fissura unilateral de lábio e palato. Lai et al. ${ }^{20}$ (2009) observaram a microdontia em $60,3 \%$ no lado fissurado e $3,9 \%$ no lado não fissurado. Em todos esses estudos, o dente mais afetado pela microdontia foi o incisivo lateral superior. Ezoddini et al. ${ }^{12}$ (2007) detectaram a frequência de 2,5\% dessa anomalia em indivíduos sem fissura. Em relação ao tratamento endodôntico, devemos ter cuidado durante as fases de abertura coronária, odontometria e preparo biomecânico, pois as dimensões estão abaixo do normal. Logo, não se recomenda fazer desgastes excessivos, principalmente com o uso de brocas, e deve-se ter atenção durante as tomadas radiográficas para que estas forneçam a real exatidão dos dentes, sem distorções ou alongamentos. 


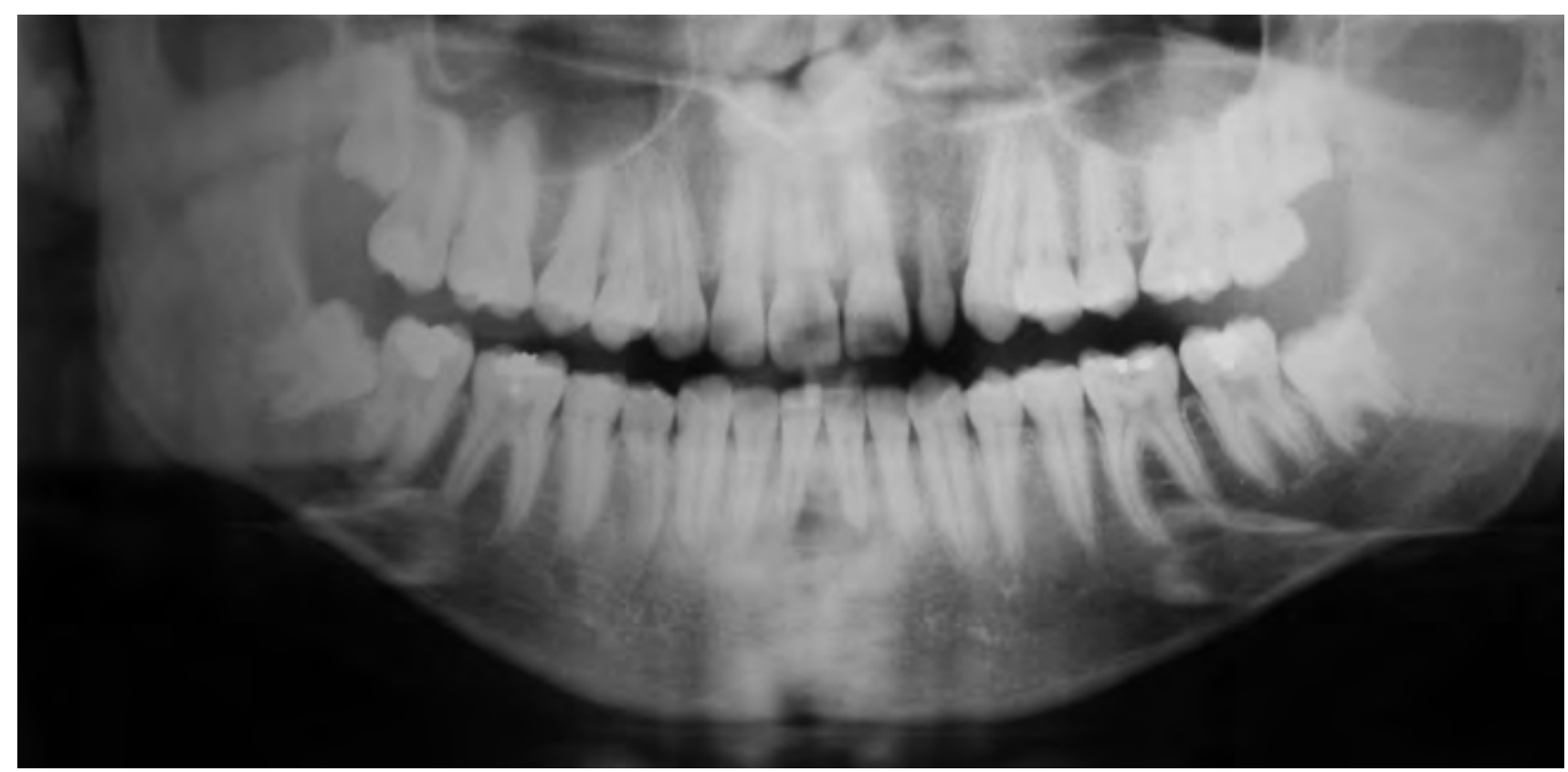

Figura 3 - Radiografia panorâmica mostrando microdontia no incisivo lateral superior esquerdo

A macrodontia, neste trabalho, não apresentou prevalência estatística significativa, nem foram encontrados estudos que mostrem a sua frequência em indivíduos com fissura. Existem outras anomalias dentárias que podem alterar o tratamento endodôntico, como a fusão, geminação, dens in dente, taurodontismo, no entanto, não estas foram encontradas nas radiografias examinadas para este estudo.

As anomalias dentárias, em geral, têm sido encontradas de forma mais prevalente em indivíduos com fissuras labiopalatinas, quando comparados com a população em geral, sendo as anomalias localizadas, na maioria das vezes, na área da fissura ${ }^{22}$. Os resultados variados na literatura podem ser explicados pela aplicação de critérios diferentes em diferentes estudos e pela falta de padronização dos dados 5 .

Portanto, ao observar esses resultados, ressalta-se a importância de o endodontista, que trabalha com indivíduos com fissuras labiopalatinas, conhecer as anomalias dentárias - na medida em que alguns indivíduos deste estudo apresentaram mais de uma anomalia -, com o objetivo de reconhecê-las precocemente, por meio de um eficiente exame radiográfico, elaborando um plano de tratamento adequado para cada caso, de modo a prever e evitar iatrogenias numa região anatômica em que a perda de um elemento dentário pode acarretar graves consequências.

\section{Conclusão}

Baseado nos dados obtidos neste estudo, concluímos que as anomalias dentárias em indivíduos com fissura transforame incisivo unilateral, como a dilaceração, a giroversão e a microdontia, são mais prevalentes no lado adjacente à fissura em comparação ao lado não adjacente, demonstrando diferen- ça estatística significativa. Além disso, concluímos que estas podem alterar o tratamento endodôntico, devendo o endodontista estar apto a reconhecê-las e tomar os devidos cuidados e precauções durante $o$ curso de tratamento.

\section{Agradecimentos}

Ao setor de Radiologia do HRAC/USP por disponibilizar e permitir a avaliação das radiografias necessárias para este estudo.

\section{Abstract}

Objective: the aim of this study was to determine the prevalence of dental anomalies on the teeth which are positioned on the side of the cleft in individuals with unilateral cleft lip and palate and relate these anomalies to the difficulties concerning endodontic treatment, when necessary. Subjects and method: the comparative analysis was realized on the teeth adjacent to the cleft and its corresponding homologues, through panoramic radiographs. The radiographic observation was analyzed by an examiner using a magnifying glass, in a vertical negatoscope in the Radiographic Interpretation Room of HRAC-USP. The sample comprised subjects whose ages ranged from 9 to 37 years, who had permanent anterior teeth, with, at least a pair of homologues, presenting coronary and radicular conservation which allowed the radiographic interpretation of the whole pulpar area, without any previous endodontic and orthodontic treatment. Results: a total of 592 panoramic radiographs were analyzed, considering that 106 were according to the inclusion criteria. The most common anomaly found was dilaceration $(78.30 \%)$, followed by rotated teeth (24.53\%), microdontia (15.09\%) and macrodontia (1.89\%). For the statistical analysis, it was applied the Fisher Exact Test, 
and only macrodontia did not present statistically significant difference. The upper central left incisor presented most anomalies (58.82\%). Male individuals presented higher prevalence $(66.04 \%)$ and most of the individuals presented unilateral cleft lip and palate on the left side (68.87\%). Conclusion: these results suggest that dental anomalies found in this study can affect the endodontic treatment and the professional must recognize them and take specific care and precautions during the treatment.

Keywords: Endodontics. Cleft palate. Panoramic radiography.

\section{Referências}

1. Al Omari F, Al-Omari IK. Cleft lip and palate in Jordan: birth prevalence rate. Cleft Palate Craniofac J 2004; 41(6):609-12.

2. Brandalize APC, Bandinelli E, Borba JB, Félix TM, Roisenberg I, Schüler-Faccini L. Polymorphisms in genes MTHFR, MTR and MTRR are not risk factors for cleft lip/palate in South Brazil. Braz J Med Biol Res 2007; 40(6):787-91.

3. Wehby GL, Murray JC. Folic acid and orofacial clefts: a review of the evidence. Oral Dis 2010;16(1):11-9.

4. Bufalino A, Paranaíba LMR, Aquino SN, Martelli-Júnior H, Swerts MSO, Coletta RD. Maternal polymorphisms in folic acid metabolic genes are associated with nonsyndromic cleft lip and/or palate in the brazillian population. Birth Defects Res Part A Clin Mol Teratol 2010; 88(11):980-6.

5. Akcam MO, Evirgen S, Uslu O, Memikoglu UT. Dental anomalies in individuals with cleft lip and/or palate. Eur J Orthod 2010; 32(2):207-13.

6. Jafarzadeh H, Abbott PV. Dilaceration: review of an endodontic challenge. J Endod 2007; 33(9):1025-30.

7. Kusgoz A, Yildirim T, Kayipmaz S, Saricaoglu S. Nonsurgical endodontic treatment of type III dens invaginatus in maxillary canine: an 18-month follow up. Oral Surg Oral Med Oral Pathol Oral Radiol Endod 2009; 107(3):e103-6.

8. Keles A, Çakici F. Endodontic treatment of a maxillary lateral incisor with vital pulp, periradicular lesion and type III dens invaginatus. Int Endod J 2010; 43(7):608-14.

9. Jamal GAA, Hazza'a AM, Rawashdeh MA. Prevalence of dental anomalies in a population of cleft lip and palate patients. Cleft Palate Craniofac J 2010; 47(4):413-20.

10. Tannure PN, Oliveira CAGR, Maia LC, Granjeiro JM, Costa MC. Prevalence of dental anomalies in non-syndromic individuals with cleft lip and palate: a systematic review and meta-analysis. Cleft Palate Craniofac J 2012; 49(2):194-200.

11. Letra A, Menezes R, Granjeiro JM, Vieira AR. Defining subphenotypes for oral clefts based on dental development. J Dent Res 2007; 86(10):986-91.

12. Ezoddini AF, Sheikhha MH, Ahmadi H. Prevalence of dental anomalies: a radiographic study. Com Dent Health 2007; 24(3):140-4.

13. Freitas JAS, Dalben GS, Santamaria Júnior M, Freitas PZ. Current data on the characterization of oral clefts in Brazil. Braz Oral Res 2004; 18(2):128-33.

14. Baroneza JE, Faria MJSS, Kuasne H, Carneiro JLVC, Oliveira JC. Dados epidemiológicos de portadores de fissuras labiopalatinas de uma instituição especializada de Londrina, estado do Paraná. Acta Sci Health Sci 2005; 27(1):31-5.
15. Yassaei S, Mehrgerdy Z, Zareshahi G. Prevalence of cleft lip and palate in births from 2003-2006 in Iran. Com Dent Health 2010; 27(2):118-21.

16. Longombe AO, Tshimbila Kabangu JMV. The epidemiological approach of clefts lip and palate in the eastern of Democratic Republic of Congo. Ann Chir Plast Esthét 2012; $57(3): 245-9$

17. Miloglu O, Cakia F, Caglayan F, Yilmaz A-B, Demirkaya F. The prevalence of root dilacerations in a Turkish population. Med Oral Patol Oral Cir Bucal 2010; 15(3):e441-4.

18. Karabucak B, Ishii H, Kratchman SI. Conventional and surgical endodontic retreatment of a maxillary lateral incisor with unusual anatomy. Int Endod J 2008; 41(6):524-31.

19. Valladares Neto J, Costa SP, Estrela C. Orthodontic-surgical-endodontic management of unerupted maxillary central incisor with distoangular root dilaceration. J Endod 2010; 36(4):755-9.

20. Lai MC, King NM, Wong HM. Abnormalities of maxillary anterior teeth in chinese children with cleft lip and palate. Cleft Palate Craniofac J 2009; 46(1):58-64.

21. Tortora C, Meazzini MC, Garattini G, Brusati R. Prevalence of abnormalities in dental structure, position, and eruption pattern in a population of unilateral and bilateral cleft lip and palate patients. Cleft Palate Craniofac J 2008; 45(2):154-62.

22. Ribeiro LL, Neves LT, Costa B, Gomide MR. Dental anomalies of the permanent lateral incisors and prevalence of hypodontia outside the cleft area in complete unilateral cleft lip and palate. Cleft Palate Craniofac J 2003; 40(2):172-5.

Endereço para correspondência:

Lidiane de Castro Pinto

Rua Silvio Marchione, 3-20 - Vila Nova Cidade Universitária

17012-900 Bauru - SP

Fone: (14) 99795-0160

E-mail: lidianedecastro@ig.com.br

Recebido: 24/11/2013. Aceito: 14/12/2013. 